\title{
Multimedia-Assisted Learning among Lebanese Teachers
}

\author{
Khayrazad Kari Jabbour \\ Modern University for Business and Science, Lebanon \\ karijabbour@hotmail.com
}

\begin{abstract}
Multimedia learning consists of graphics and texts. Learning occurs when the learners create mental representations from combining the text and relevant graphics in the lessons. Incorporation of multimedia learning in teaching can lead education to a higher level than traditional teaching techniques. The aim of this study is to investigate the extent to which multimedia is incorporated in classroom teaching among Lebanese educators. A small scale survey from 50 middle school teachers of 10 different schools selected from various areas in Lebanon was undertaken. The survey results were compared and tested in order to evaluate whether or not the teachers integrate multimedia in classroom teaching. If they do, this study aims to identify the multimedia elements they frequently use. However, if not, this study aims to find out the causes for not adopting multimedia in their classroom teaching.
\end{abstract}

Keywords: Active Learning, Cognitive Theory, Instruction, Graphics, Learning engagement, Multimedia-assisted instruction, Technology education

\section{Introduction}

In teaching, it is normal to use printed or spoken words as the primary way for conveying information. Words are simple, easy and inexpensive to utilize. However, in the other hand, research has shown that multimedia learning can improve learners' understanding. Multimedia learning consists of graphics (drawings, charts, photographs, animation, and video) and texts (printed and spoken texts). Multimedia learning principles occur when the learners create mental representations from combining text and relevant graphics simultaneously. There are strong and reliable evidence which prove that learners obtain more knowledge from words and graphics than from words alone. Researchers confirm that students' brains can organize facts from several setting modes into meaningful knowledge. It can also combine facts from verbal and non-verbal information into a mental model. Moreno \& Mayer explain that the instructional designers need to choose different setting modes or style, in order to enhance learning (Moreno \& Mayer, 2000). In this article we investigate the extent to which multimedia is incorporated in Lebanese classrooms. A survey from 50 middle school teachers of 10 different schools was undertaken. The survey results were taken into consideration to find the extent of which multimedia learning is applied in Lebanese classrooms.

Reasons for Multimedia: Multimedia supports the way the human brain learns efficiently. In 2005, Mayer defined the Cognitive Theory of Multimedia Learning (CTML); the theory illustrates how to build multimedia instructional using cognitive science strategies to combine words and graphs in ways that maximize learning efficiency. The CTML analyzes how to help the human brain learn efficiently, taking into consideration a number of fields including psychology, neuroscience, artificial intelligence, computer science, linguistics, philosophy, and biology. This science explores and analyzes the human mental process such as perceiving, thinking, remembering, understanding, and learning (Stillings, Weisler, Chase, Feinstein, Garfield, \& Rissland, 1995). The Cognitive Theory of Multimedia Learning (CTML) highlights the notion that the human brain attempts to learn more efficiently than they could have with words or graphs alone (Mayer, 2009).

Lebanon: Lebanon is a small democratic country located on the east of the Mediterranean Sea. It stretches over a tiny territory of 10,452 square meters (ESIS, 2001). In 2009 The Bureau of Near Eastern Affairs estimated the population of Lebanon to be a little less than 4 million, including a wide range of diversity. There are at least 18 different religious sects and 19 different political parties (Bureau of Near Eastern 
Affairs, 2008). The current Lebanese constitution was written in 1926 and specifies a unique political system based on a balance of political power among the various religious groups.

\section{Lebanese Education Institutes}

The majority of the Lebanese classroom is traditional lecture classroom format. In the classroom hierarchy places the teacher at the top. Lebanese learners expected to speak up only when invited to do so by the teacher, to follow a strict order, to respect the teacher at all times, to listen to the teacher giving lectures. Most Lebanese education institutes promote seclusion; where the principal take control over all the teachers, school policy and classroom decisions, and the teacher in the instruction role transmitting the curriculum package to the students utilizing the lecturing approach.
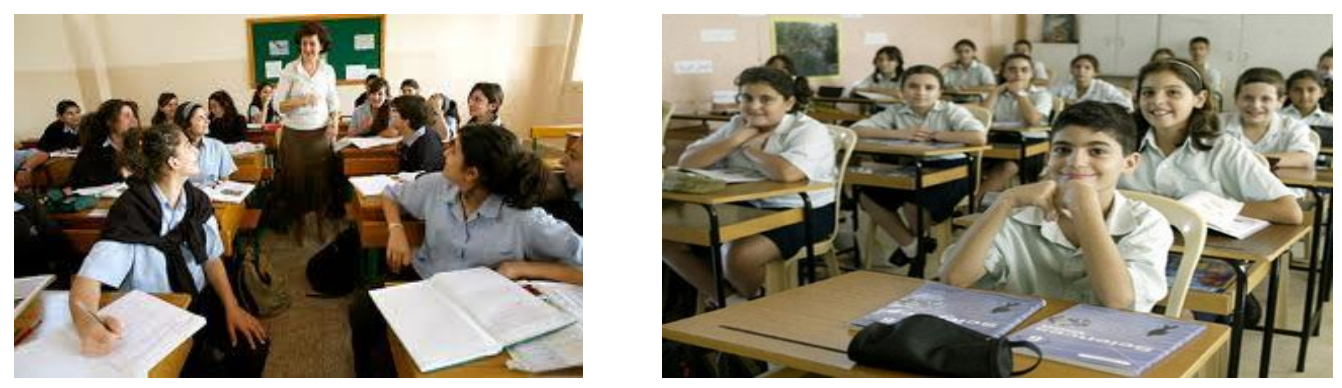

\section{Research Study}

Research Questions: In this research study, the following are the guiding research questions:

- Are the teachers integrating multimedia learning in their classrooms? If yes, to what extent? If no, what are the reason(s) of not integrating multimedia learning in classrooms?

- What are the teachers' attitudes on the benefit(s) of integrating multimedia in classroom teaching?

- What are the limitation(s) of integrating multimedia in classroom teaching?

\section{Methodology}

First of all, it is important to note that this research study is a small-scale and not professional research on a 'large-scale'. The instrument in this study was a paper survey that was used to gather data from 50 middle school teachers from 10 schools ranging from middle to secondary schools selected from various areas in Lebanon. Participants completed a 10 minute surveys. The schools chosen for this study were located in urban areas with diverse populations, representing an array of ethnicities and socio-economic levels. The teachers from all schools were treated as a single group; therefore no distinction was made among the schools. This study was conducted in a manner that protected the confidentiality of the participants. The instrument used in this study was a questionnaire administered in paper and pencil form. The study gathered quantitative data to answer the research questions. Survey items were developed specifically for this purpose and it was based on an extensive literature review. The questionnaire containing five questions; different question-types such as likert scale and open-ended were used in the questionnaire. Questionnaire were 1) Demographic, 2) The extent of intergrading multimedia in classroom teaching, 3) The advantage(s) of using multimedia in classroom teaching, 4) The limitation(s) of integrating multimedia in classroom teaching, and 4) Reason(s) for not integrating multimedia in classroom teaching. The questionnaire was piloted to a group of 10 teachers in order to assess its validity before distributing it to the respondents.

\section{Data results and discussion}

Incorporate multimedia in classroom teaching: The majority of the teachers surveyed (91\%) reported that they never incorporate multimedia in their classroom teaching; $2 \%$ ) of the teachers surveyed reported that they sometimes incorporate multimedia in their teaching sometimes, and (7\%) of the teachers surveyed reported that they often incorporate multimedia in their teaching. From the findings, it can be seen that there 
are an urgent need of integrating multimedia in classroom teaching. The Lebanese schools utilize fairly traditional learning materials. The main source of information in the classroom teaching is the textbooks, and the teacher's knowledge of the subject matter. Textbooks considered being the main element in the classroom teaching even though it often provides outdated information. Additionally, teacher is regard as the only provide of knowledge to students. The teacher domination the instructional process, the content is delivered to the entire class and the teacher tends to emphasize on factual knowledge. The students need to listen passively in the learning process.

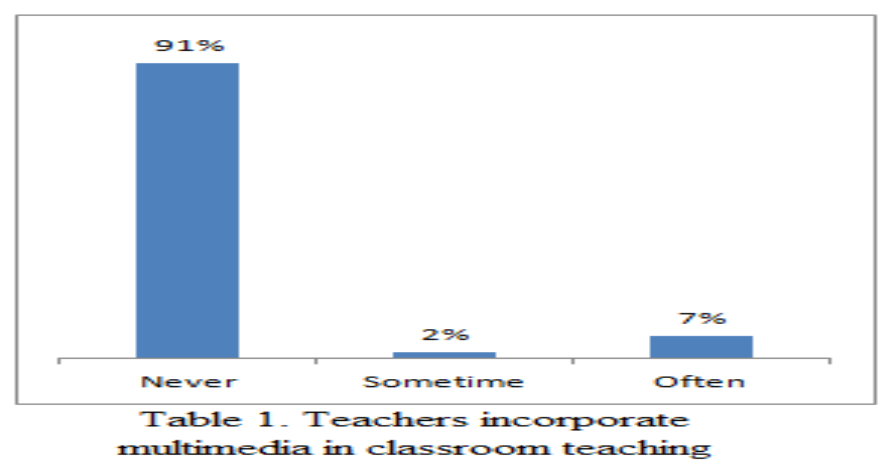

Multimedia resources in schools: Access to resources in schools is a necessary condition to the integration of multimedia in teaching. The results of the survey indicated that the majority of the teachers $(93 \%)$ reported that their classrooms lack the technology resources needed in order to integrate multimedia in classroom teaching. (5\%) of the teachers reported that their classrooms has the technology resources needed in order to integrate multimedia in classroom teaching, and (2\%) undecided. Based on the findings, it can be seen that there are there are some clear obstacle that hindered teachers from incorporating multimedia in their classroom teaching. Some teacher commented that their schools did not have technology resources in the classroom. For that reason, they require to use the technology lab in order to integrate multimedia in the lesson. Some teacher commented that use of the technology lab is restricted due to the reason that the technology labs mostly were occupied by the superior teachers.

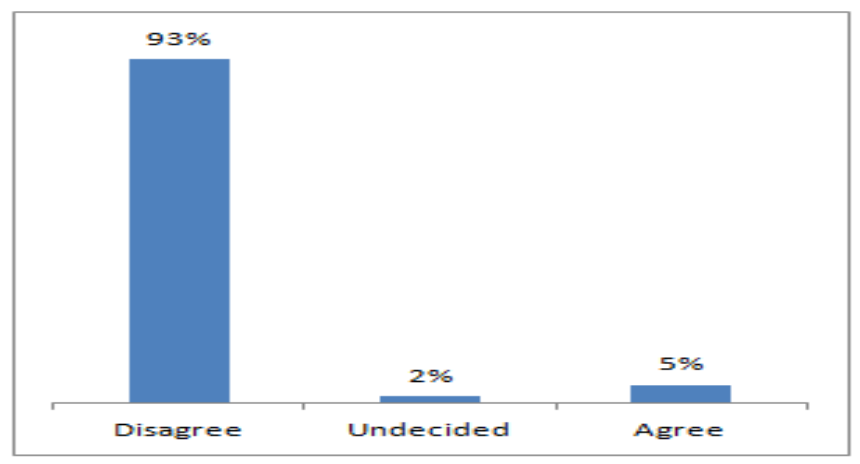

Table 2. Multimedia resources in schools

Teacher's attitudes toward multimedia-assisted learning: Multimedia-assisted learning has many advantages than the traditional way of education. The main advantage of Multimedia-assisted learning is to reduce learners' waste of time and efforts, and to create more practical and task-oriented lessons. The results of the survey indicated that the majority of the teachers, who participated in the survey, (82\%) agree that the integration of multimedia-assisted learning can be a valuable resource for educational tasks; (18\%) were neutral, and no one disagree. For example, many teachers' commented: "that Multimedia-assisted learning can make the lessons more interactive and appealing to the students"; "they are always looking for new ways to educate their students"; "multimedia can be used to help to make lessons interesting, and more effective"; "using multimedia elements can make difficult information easier to understand". The teachers also sent a loud message to Lebanese Department of Education: "pay closer attention to what teachers need". The 
teachers face issues and challenge because of the lack of resources and the needed in the classroom. Teachers' attitudes and opinions regarding Multimedia-assisted learning is another area that deserves further study. Many pre-existing factors, such as Teachers attitudes, will determine successful technology integration in an educational setting.

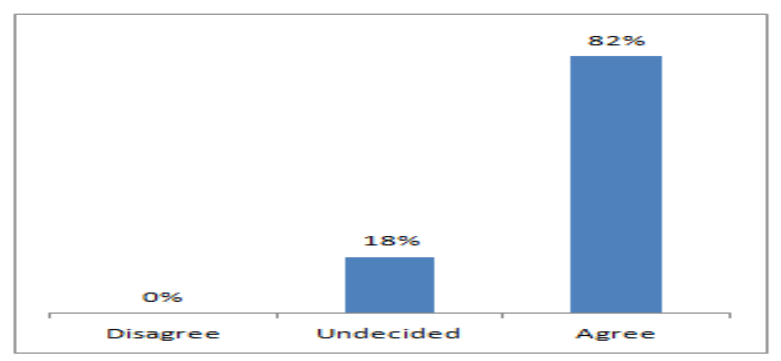

Table 3. Teachers attitudes toward multimediaassisted learning

Professional development: Teachers' professional development is a key factor in successful integrating of multimedia in classroom teaching. Without a doubt, it is crucial to train teachers to apply multimedia teaching approach in their lectures in order to be able to use it to supplement their teaching activities. The results of the survey indicated that the all of the teachers $(100 \%)$ reported that they never had professional development training on how to integrate multimedia in teaching the classroom. Based on the findings, it can be seen that there is a serious need for professional development training in order to assist teachers in adopting multimedia in teaching the classroom.

\section{Conclusion}

Multimedia instructional design combines words and graphics to enhance learning effectiveness. Using Multimedia instruction can help learners engage in active learning. However, in Lebanon, the use of technology and multimedia is still in its early stage in the education system due to the inadequate resources and professional development training. The majority of the teachers surveyed (91\%) reported that they never incorporate multimedia in their classroom teaching. (93\%) of the teachers surveyed reported that their classrooms lack the technology resources needed in order to integrate multimedia in teaching. (100\%) of the teachers reported that they have never had professional development training on how to integrate multimedia in teaching the class. Lebanese educational systems need to be updated and upgraded. An area of further research should focus on the teachers' attitudes and opinions regarding Multimedia-assisted learning. Teachers have to accept the fact that teaching is no longer limited to the walls of their classrooms or even the resource centers, such as the libraries and technology labs. Many pre-existing factors, such as teachers' attitudes, will determine successful technology integration in an educational setting. The Lebanese Ministry of Education should investigate the potential of information and communication technologies. From the results of the study, the Lebanese Ministry of Education should consider improving technology in the classrooms. It is difficult to change the Lebanese educational system and build successful learners in a short period. However, it is possible to some extent by taking some initiative through teacher professional development. The Lebanese Ministry of Education should consider providing the teacher training programs so that more emphasis can be put on equipping the teachers with the right knowledge of technology, specifically multimedia learning in order to improve students' learning in the classroom. Multimedia learning methods should be adapted in the education curricula of the country. The Lebanese Education system should expose the Lebanese youth to the opportunity to inductively build and strengthen their knowledge, skills and expertise.

Limitation: A replication of the study reported here to a larger sample might yield different results. The implications of the problems and challenges identified in this study beg for further research, more focussed education policies, and more support for teachers to improve pupils' opportunity-to-learn. The findings of this study should be interpreted with caution because of the small number of teachers who participated in the study. 


\section{Reference}

Mayer, R. E. (2009). Multimedia learning (2nd Ed.). New York: Cambridge University Press.

Moreno, R. \& Mayer, R. E. (2000a). A coherence effect in multimedia learning: The case for minimizing irrelevant sounds in the design of multimedia instructional messages. Journal of Educational Psychology, 92, 117-125.

Stillings, N. A., Weisler, S. E., Chase, C. H., Feinstein, M. H., Garfield, J. L. \& Rissland, E. L. (1995). Cognitive science: An introduction (2nd Ed.). Cambridge, MA: MIT Press. 